\title{
Causal inference in secondary analysis of a randomized controlled trial
}

\author{
Wenchen $\mathrm{Li}^{*}$ and Shijun Li
}

(c) 2019 Springer-Verlag GmbH Germany, part of Springer Nature

\section{Dear Editor,}

We read with great interests on the secondary analysis of the NUTRIREA-2 trial [1]. The study found that early enteral nutrition was associated with increased plasma citrulline concentration and intestinal fatty acid binding protein (I-FABP) concentration. While the former association indicated increased enterocyte mass, the latter indicated ischemic enterocyte damage. The authors discussed a lot on this point and proposed several hypotheses to explain this phenomenon. However, we felt that more analysis can help to figure out this conundrum. First of all, we need to confirm there is real positive association of enteral nutrition and increased citrulline. Since the study is a secondary subgroup analysis (e.g. not all patients included in NUTRIREA-2 trial were included for the present analysis), false positive is very likely to present. One way to exclude such false positive finding is to perform dose response analysis. In the Grading of Recommendations Assessment, Development and Evaluation (GRADE) framework, the presence of doseresponse relationship can increase the level of evidence [2]. It would be more confident for a statistical association to be a causation in the presence of dose-response relationship. In this study, it would be easy to examine whether there is dose-response relation between enteral nutrition and the plasma citrulline concentration. Secondary, the causal mediation analysis can also help to investigate the association of I-FABP and ischemic events [3]. In this framework, the ischemic event as recorded in the NUTRIREA-2 trial can be considered as end point, and the change in I-FABP between day 3 and day 0 can be considered as a mediator. The model will give an estimate on the proportion of effect that is mediated via the reduction in I-FABP. Such further analyses will not necessarily confirm the association is causation, but will add more robustness to the conclusion.

\section{Compliance with ethical standards}

Conflicts of interest

There is no conflict of interest.

\section{Publisher's Note}

Springer Nature remains neutral with regard to jurisdictional claims in published maps and institutional affiliations.

Accepted: 26 June 2019

Published online: 3 July 2019

\section{References}

1. Piton G, Le Gouge A, Brulé N et al (2019) Impact of the route of nutrition on gut mucosa in ventilated adults with shock: an ancillary of the NUTRIREA-2 trial. Intensive Care Med 39:899-900. https://doi.org/10.1007/s0013 4-019-05649-3

2. Atkins D, Best D, Briss PA et al (2004) Grading quality of evidence and strength of recommendations. BMJ 328:1490. https://doi.org/10.1136/ bmj.328.7454.1490

3. Zhang Z, Zheng C, Kim C et al (2016) Causal mediation analysis in the context of clinical research. Ann Transl Med 4:425-4250. https://doi. org/10.21037/atm.2016.11.11

\footnotetext{
*Correspondence: liwenchen999@163.com

Department of Neurology, Affiliated Dongyang Hospital of Wenzhou Medical University, 60 Wuning West Road, Dongyang, Zhejiang 322100, People's Republic of China
} 